\title{
PENGGUNAAN HEAT PIPE PERSEGI DAN SIRIP UNTUK MENINGKATKAN PERFORMANCE PADA FLAT PLATE SOLAR COLLECTOR
}

\author{
Rabiatul Adawiyah(1), M. Khafidz Arifin ${ }^{(1)}$ \\ rabiatulpoltek@yahoo.com, hfidz.allianz@gmail.com
}

\section{(1) Staf Pengajar Progam Studi Teknik Alat Berat Politeknik Negeri Banjarmasin}

\begin{abstract}
Based on the review of references from journals, and review of the literature supporting this research, state of art the underlying issue of solar collectors in particular types of flat plate solar collector how to improve performance such as efficiency the collector can be increased maximum. In improving this performance history researchers perform a variety of ways, that is modification, add fixtures, test material used etc. From the results of research related to the problem of the increase in performance use of hosepipes connected with the use of heat pipe absorber all round. This raises a hypothesis in which the surface directly exposed to hot sun or in contact with the absorber a little part of the arch so that the surface area too small conduction, if used pipes square shape is expected to occur heat absorption is better because of surface conduction wider and coupled with a fin heat sink.

Based on the above, the underlying issue is the increase in performance generated in the form of heating efficiency, is to examine how they affect the use of heat pipe square and added $a$ fin on the top to the increased performance of the solar collector.

The results of this study found that the performance of solar collector that uses square pipe equipped with fins better than solar collector with a round pipe
\end{abstract}

Keywords : Flat Plate Solar Sollector, Performance Heat Square Pipe, fins, Efficiency

\section{PENDAHULUAN}

\section{Latar Belakang}

Energi matahari adalah radiasi yang dihasilkan oleh reaksi fusi nuklir di inti matahari. Radiasi ini dalam perjalanannya ke bumi melalui ruang dalam bentuk energi yang disebut foton. Meskipun hanya 30\% dari tenaga surya benar-benar mencapai bumi, setiap 20 menit matahari menghasilkan daya yang cukup untuk memasok Bumi dengan kebutuhan untuk satu tahun penuh. (Grigorios lordanou 2009)

Sumber energi terbarukan seperti energi matahari ini dapat digunakan melebihi untuk kebutuhan energi manusia (Taki, Ajabshirch, Behfar, \& Taki, 2011). Energi matahari sebagai salah satu bentuk yang paling signifikan dari sumber energi terbarukan telah menarik banyak perhatian karena ada keyakinan yang dapat memainkan peran yang sangat penting dalam memenuhi bagian utama dari kebutuhan energi di masa depan (Hedayatizadeh et al, 2013)

Manfaat yang paling penting dari sistem energi terbarukan adalah penurunan pencemaran lingkungan. Krisis biaya energi dan permintaan meningkat secara eksponensial dengan energi fosil yang hampir habis untuk tersedia di waktu mendatang serta pencemaran lingkungan dan udara menjadi lebih parah, sehingga ada kecenderungan permintaan yang tinggi untuk menggunakan atau menghasilkan energi dengan biaya murah atau terbarukan, bersih dan rendah untuk menghadapi krisis ini. ( Ali dalam Hossein Chaji 2013)

Dalam beberapa tahun terakhir energi surya digunakan sebagai sumber energi yang layak untuk menggantikan energi yang bersumber dari fosil . Salah satu aplikasi yang paling sederhana dan langsung dari energi ini adalah konversi dari radiasi matahari menjadi panas. Oleh karena itu sebagai suatu cara di sektor domestik yang dapat mengurangi dampak terhadap lingkungan adalah dengan pemasangan kolektor surya plat datar untuk memanaskan air. Meskipun kita ketahui bahwa beberapa kolektor ini telah berkembang selama 40 sampai dengan 50 tahun terakhir tanpa banyak perubahan yang signifikan dalam desainnya serta prinsipprinsip operasionalnya. (Grigorios lordanou, 2009)

Budiman Sudia (2010) menjelaskan bahwa energi matahari merupakan salah satu energi terbarukan yang memiliki potensi untuk dikelola dan dikembangkan khususnya 
pada daerah dengan intensitas matahari yang cukup tinggi. Untuk memanfaatkan energi matahari tersebut dibutuhkan suatu alat yang dikenal dengan kolektor surya. Kolektor surya plat datar merupakan salah satu jenis kolektor yang banyak digunakan karena memiliki konstruksi yang relatif lebih sederhana dibandingkan dengan jenis yang lain. Salah satu pemanfaatan dari kolektor plat datar adalah sebagai pemanas air.

Alok Kumar (2014) meneliti flat plate solar collector, menggunakan sejumlah arrays of circular cross sectional tube yang melingkar dan melekat pada tabung absorber untuk mentransfer panas dari tabung absorber ke fluida kerja. Ketika digunakan semi circular type tube yang menekan pelat absorber, menyebabkan bidang kontak antara fluida dan absorber flate sangat dekat. Karena alasan ini performance kolektor surya plat datar meningkat.

Ramadhani Bakari et al (2014) menyelidiki pengaruh ketebalan material kaca pada kinerja kolektor surya pelat datar. Performance kolektor surya dipengaruhi oleh glaze transmittance, absorptance, dan reflektansi yang hasilnya menjadi kerugian panas utama dalam sistem. Empat model kolektor surya dengan ketebalan kaca yang berbeda dirancang, dibangun, dan diuji untuk melihat perfomance dari semua kolektor. Hasil penelitian menunjukkan bahwa ada pengaruh dalam perbedaan ketebalan kaca terhadap performance kolektor. Collector dengan kaca tebal $4 \mathrm{~mm}$ memberikan efisiensi terbaik dari $35,4 \%$ dibandingkan dengan kaca tebal $6 \mathrm{~mm}$ hanya $27,8 \%$.

Vishal Dabra (2013) memodifikasi tabung kolektor surya udara untuk sudut kemiringan kolektor berbeda dari horisontal dengan kecenderung pada $30^{\circ}$ dan $45^{\circ}$. Hasil penelitian menunjukkan bahwa sudut kemiringan memiliki pengaruh yang signifikan terhadap performance tabung termal kolektor surya dengan atau tanpa reflektor. Percobaan juga menunjukkan bahwa, selama $30^{\circ}$ sudut kemiringan tabung kolektor surya dengan reflektor memiliki thermal performance yang lebih baik dari sudut kemiringan $45^{\circ}$ dievakuasi dengan atau tanpa reflektor.

Kumar and Prasad (2000,) melakukan penelitian dengan menambahkan twisted taper di sebuah kolektor surya. Mereka meneliti efek dari geometri twisted-tape, laju aliran massa yang berbeda dan intensitas radiasi matahari pada kinerja termal. Para penulis mengamati bahwa kehilangan panas berkurang (karena nilai yang lebih rendah dari suhu plate) dan akibatnya peningkatan pada efisiensi termal diamati.

\section{Review Penelitian Terdahulu}

Budiman Sudia (2010) melakukan penelitian untuk menentukan pengaruh penggunaan dua cermin datar terhadap energi berguna pada kolektor pemanas air plat datar, dimana hasilnya adalah Penggunaan konsentrator dua cermin datar akan meningkatkan energi berguna kolektor. Untuk kolektor yang menggunakan cermin energi berguna rata-rata $=507.8$ Watt sedangkan kolektor tanpa cermin energi berguna rata-rata $=351.8 \mathrm{Watt}$.

Ramadhani Bakari et al (2014) dalam penelitiannya Effect of Glass Thickness on Performance of Flat Plate Solar Collectors for Fruits Drying menyelidiki pengaruh ketebalan material kaca pada kinerja kolektor surya pelat datar. Performance kolektor surya dipengaruhi oleh glaze transmittance, absorptance, dan reflektansi yang hasilnya menjadi kerugian panas utama dalam sistem. Empat model kolektor surya dengan ketebalan kaca yang berbeda dirancang, dibangun, dan diuji untuk melihat perfomance dari semua kolektor. Hasil penelitian menunjukkan bahwa ada pengaruh dalam perbedaan ketebalan kaca terhadap performance kolektor. Collector dengan kaca tebal $4 \mathrm{~mm}$ memberikan efisiensi terbaik dari $35,4 \%$ dibandingkan dengan kaca tebal $6 \mathrm{~mm}$ hanya $27,8 \%$

H Vettrivel dan P Mathiazhagan (2013) dalam penelitiannya Thermal Performance Optimazion of a Flat Plate Solar Water Heater Collector Using Matlab dimana penelitian ini menyajikan model matematika satu dimensi untuk mensimulasikan proses transient yang terjadi pada kolektor surya plat datar. Model ini bergantung pada waktu sifat panas fisik dan koefisien perpindahan panas dan didasarkan pada memecahkan persamaan yang menggambarkan konversi energi untuk kaca penutup, celah udara antara penutup dan absorber, penyerap, fluida kerja, isolasi, dan tangki penyimpanan. Persamaan diferensial yang diselesaikan dengan menggunakan metode terbatas-perbedaan implisit dalam skema berulang dan dieksekusi dengan menggunakan MATLAB. Dalam rangka untuk memverifikasi metode yang diusulkan, percobaan dirancang dan dilakukan selama beberapa hari dengan kondisi ambien variabel dan laju aliran Perbandingan antara hasil dihitung dan diukur dari temperatur fluida sementara di outlet kolektor menunjukkan konvergensi yang memuaskan. Metode yang diusulkan adalah sesuai untuk verifikasi absorber dan kaca mencakup efektivitas, dan untuk menghitung efisiensi keseluruhan sistem bersama dengan faktor kehilangan panas secara keseluruhan. 
Atish Mozumder et al (2014) dalam penelitiannya Study of Cylindrical Honeycomb Solar Collector menyajikan hasil investigasi pada Cylindrical Honeycomb Solar Collector Honey comb dibuat transparan dari triasetat selulosa polimer. Karakteristik isolasi dari sarang lebah yang dipelajari dengan memvariasikan pemisahan antara sarang lebah dan pelat absorber. Nilai optimal pemisahan ditemukan $3.3 \mathrm{~mm}$, dimana koefisien perpindahan panas pada $3.06 \mathrm{~W}^{-1} \mathrm{~m}^{-}$ ${ }^{2} \mathrm{~K}^{-1}$. Hal ini mendukung hasil eksperimen serupa sebelumnya. Menemukan bahwa ketika sudut datang radiasi matahari adalah $20^{\circ}$ maka kinerja sistem dengan honeycomb lebih baik daripada yang tanpa honeycomb

E. Azad (2008) dalam judul penelitiannya Interconnected Heat Pipe Solar Collector dimana dalam tulisannya berkaitan dengan kinerja pipa panas kolektor surya. Kolektor surya terdiri dari pipa panas saling berhubungan sehingga dapat mengurangi biaya produksi dengan menggunakan pipa panas saling berhubungan karena semua pipa panas dapat dievakuasi, disegel dan diuji sekaligus. Kinerja prototipe dari pipa panas kolektor surya eksperimen diperiksa, dan hasilnya dibandingkan dengan yang diperoleh melalui analisis teoritis. Hasil yang ditunjukkan dalam kertas tampak layak

Raj Thundil Karuppa R et al (2012) dalam penelitiannya Experimental Investigation of a New Solar Flat Plate Collector, menguji Sebuah pemanas air tenaga surya baru dan murah. Kolektor adalah jenis sandwich. Penyerap terbuat dari 2 lembar GI $(1 \mathrm{~mm})$ dengan kanal yang terintegrasi, dicat silika berbasis cat hitam. Percobaan telah dilakukan untuk menguji kinerja kedua pemanas air di bawah sirkulasi air dengan pompa kecil dan hasilnya dibandingkan. Hasil penelitian menunjukkan bahwa sistem dapat mencapai tingkat yang memuaskan efisiensi

Johan Vestlund (2012) dalam penelitian desertasi Gas filled, flat plate solar collectors diman penelitian ini memperlakukan kinerja termal dan mekanik pengisisn gas pada kolektor surya plat datar untuk mencapai kinerja yang lebih baik dari kolektor yang berisi udara biasa. Gas yang diuji adalah argon, krypton dan xenon yang semua memiliki konduktivitas termal lebih rendah daripada udara. Hasil terbaik dicapai dengan gas xenon yang mengisi pada absorber dengan ketebalan normal, yaitu rata-rata $0,25 \mathrm{~mm}$ dari absorber tembaga. Kinerja thermal yang baik juga dapat dicapai dengan menggunakan material absorber tembaga yang tebalnya kurang dari 0,1 mm dan untuk argon, masih memberikan kinerja operasional yang lebih baik daripada yang umum, udara kolektor diisi pada absorber dengan ketebalan $0,25 \mathrm{~mm}$.

Yuhazri, M.Y et al (2012) dalam penelitiannya Experimental Study on Effect of Reflector Bed Designs Heated by Direct Solar Radiation for Hot Water Storage System, dimana tujuan dari penelitian ini adalah untuk mengetahui performance dari perbedaan reflektor, terhadap panas langsung radiasi matahari pada water storage system. Hasil dari percobaan adalah terjadi peningkatan efisiensi dengan menggunakan curve reflektor.

D. Bhandari dan Dr. S. Singh (2012) dalam penelitianntya Performance Analysis of Flat Plate Solar Air Collectors With and Without Fins, Membadingkan performance dari tipe yang berbeda dari flat plate solar air heaters, adalah menguji tiga buah tipe dari solar air heater, yaitu conventional solar air heater, double glazing single pass solar air heater dan doubel pass solar air heater dengan internal fins, hasl pengujian menunjukkan bawah double pass finned solar air heater memiliki efisiensi tertinggi.

\section{Permasalahan}

Berdasarkan latar belakang yang telah dipaparkan sebelumnya yang bersumber dari sebagai hasil-hasil kajian referensi dari jurnaljurnal dan juga tinjuan pustaka yang mendukung penelitian ini, bawah state of art permasalahan yang mendasar dari kolektor surya khususnya jenis flat plate solar collector adalah bagaimana meningkatkan performance berupa efesiensi dari kolektor tersebut bisa ditingkatkan semaksimal mungkin. Dalam meningkatkan performance ini peneliti-peneliti terdahulu melakukan berbagai macam cara, baik memodifikasi, menambah perlengkapan, menguji material yang dipakai dan sebagainya. Dari semua telaah jurnal-jurnal yang berkaitan dengan permasalahan peningkatan performance ini penggunaan pipa air yang terhubung dengan absorber menggunakan pipa bulat, dan langsung bersentuhan dengan isolator pada bagian bawah pipa, sehingga menyebabkan kurang efektifnya konduksi panas yang mengalir dari absorber ke pipa, selanjutnya karena bagian bawah langsung bersentuhan dengan isolasi sehingga luas permukaan konduksi dari pipa ke isolasi besar tentu ini juga merupakan kerugian energi dari kolektor.

Pada penelitian ini, berdarkan permasalahan yang mendasar tersebut diatas yaitu peningkatan performance berupa efisiensi pemanasan yang dihasilkan, adalah 
untuk menguji :bagaimana pengaruhnya penggunaan pipa persegi dan ditambahkan sirip pada bagian bawahnya terhadap peningkatan performance dari kolektor surya tersebut

\section{Tujuan}

Tujuan dari penelitian ini adalah mengetahui pengaruh penggunaan pipa persegi yang ditambahkan sirip pada bagian bawahnya, serta mengetahui pengaruh terhadap peningkatan performance berupa efisiensinya. Luaran dari penelitian ini adalah menghasilkan suatu prototipe flat plate solar collector dengan indikator performance yang lebih baik dari sebelumnya.

\section{METODOLOGI PENELITIAN}

\section{Diagram Alir Peneliitan}

Sistematika penelitian perlu jelas dan terarah sehingga langkah-langkah penelitian terstruktur dengan langkah kerja yang berurutan sehingga benar-benar mendapatkan data-data yang akurat dari penelitian ini. Hal ini tergambar pada diagram alir penelitian sebagai berikut:

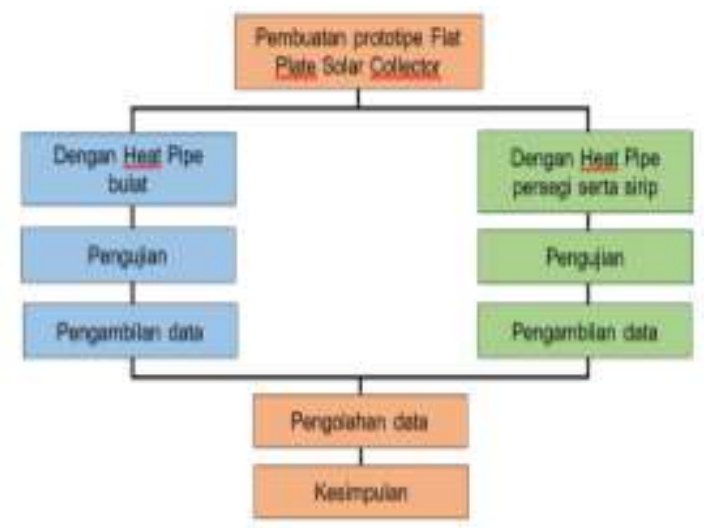

\section{Rancangan Model Prototipe}

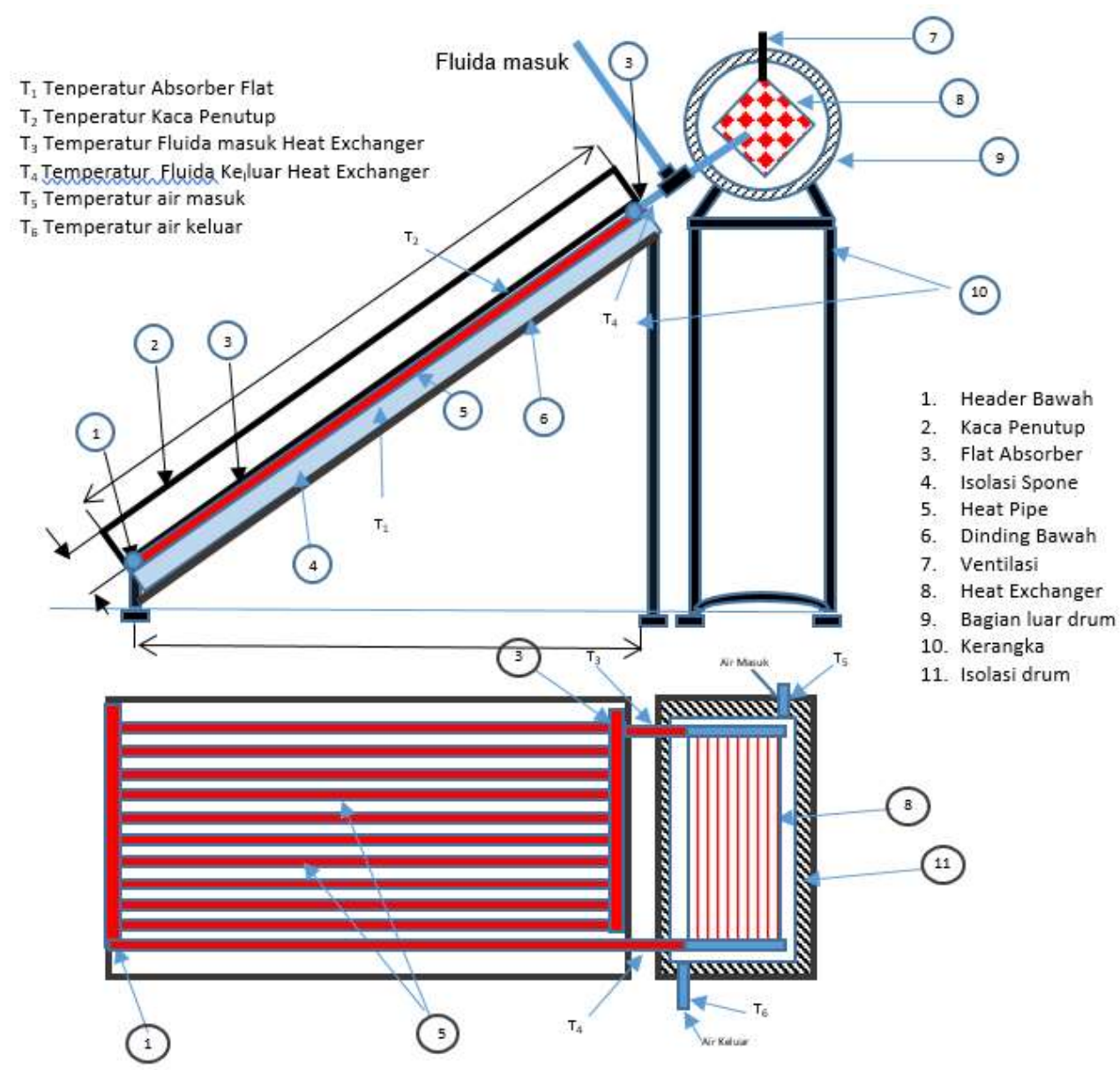

Gambar 2. Protottipe 


\section{Pengukuran Variabel}

Pengujian dilakukan secara bersamaan pada Flat Plate Solar Collector yang menggunakan pipa persegi dengan sirip dan yang menggunakan pipa bulat, pada kondisi yang sama. Pengujian dilakukan mulai jam 11 sampai dengan jam 17.00 dan mencatat setiap 15 menit variabel yang diukur. Variabel yang diukur dalam penelitian ini meliputi suhu inlet dan outlet, suhu lingkungan dan total transfer energi ke dalam tangki air

Kolektor diinstumentasi dengan dua sensor termometer untuk mengukur suhu inlet dan outlet kolektor titik keluar. Suhu lingkungan diukur menggunakan termometer inframerah di sekitar tempat penyerapan dari sinar matahari langsung. Desain adalah sama baik dari aliran maupun ukuran pipa pemanas untuk menjamin perbandingan yang akurat.

\section{Pengolahan Data}

Pengolahan data dengan uji statistik yaitu beda rata-rata uji t pada perbandingan flat plate solar collector dengan pipa bulat tanpa sirip dengan flat plate solar collector dengan pipa persegi dengan sirip. Variabel yang di bandingkan adalah perbedaan temparatur air masuk dan keluar, yang merupakan nilai yang berbanding lurus dengan efisiensi.

\section{HASIL DAN PEMBAHASAN}

\section{Grafik Hasil Pengujian Solar Collector Pipa Segi Empat dan Sirip}

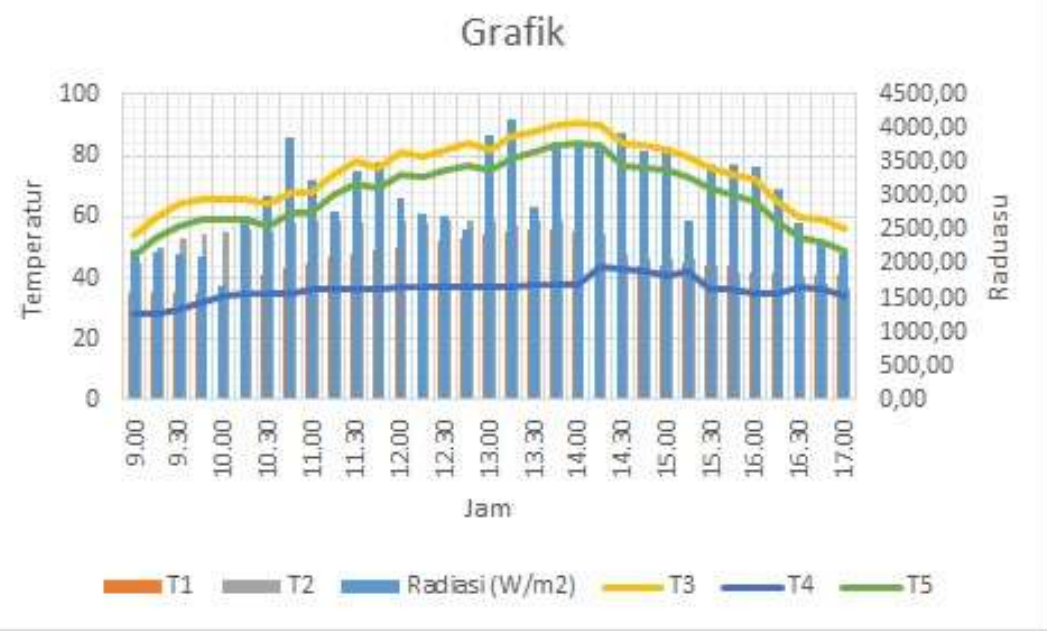

Gambar 3. Grafik Solar Collector Pipa Segia Empat dan Sirip

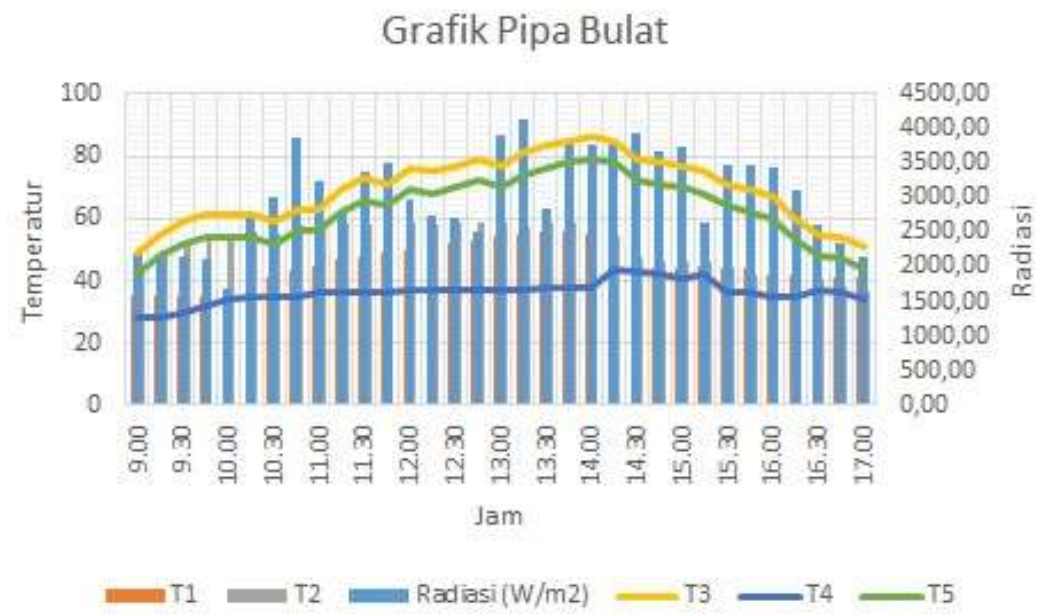

Gambar 4. Grafik Solar Collector Pipa Bulat 


\section{Pengujian Statistik Selisih Temperatur Air masuk dan Keluar Kedua Prototipe}

Paired Samples Statistics

\begin{tabular}{|ll|r|r|r|r|}
\hline & \multicolumn{1}{|l|}{ Mean } & N & Std. Deviation & \multicolumn{1}{l|}{ Std. Error Mean } \\
\hline Pair 1 & Pipa Segiempat & 30,9091 & 33 & 8,38661 & 1,45992 \\
& Selisih temp & 26,0000 & 33 & 8,48160 & 1,47646 \\
\hline
\end{tabular}

Paired Samples Correlations

\begin{tabular}{|ll|r|r|r|}
\hline & N & Correlation & \multicolumn{1}{c|}{ Sig. } \\
\hline Pair 1 & $\begin{array}{l}\text { Pipa Segiempat \& Selisih } \\
\text { temp }\end{array}$ & 33 &, 998 &, 000 \\
\hline
\end{tabular}

Paired Samples Test

\begin{tabular}{|c|c|c|c|c|c|c|c|c|c|}
\hline & & \multicolumn{5}{|c|}{ Paired Differences } & \multirow[b]{3}{*}{$\mathrm{t}$} & \multirow[b]{3}{*}{ df } & \multirow[b]{3}{*}{ Sig. (2-tailed) } \\
\hline & & \multirow[b]{2}{*}{ Mean } & \multirow{2}{*}{$\begin{array}{l}\text { Std. } \\
\text { Deviation }\end{array}$} & \multirow{2}{*}{$\begin{array}{l}\text { Std. Error } \\
\text { Mean }\end{array}$} & \multicolumn{2}{|c|}{$\begin{array}{l}\text { 95\% Confidence } \\
\text { Interval of the } \\
\text { Difference } \\
\end{array}$} & & & \\
\hline & & & & & Lower & Upper & & & \\
\hline Pair 1 & $\begin{array}{l}\text { Pipa } \\
\text { Segiempat } \\
\text { - Selisih } \\
\text { temp }\end{array}$ & 4,90909 & ,52223 & 09091 & 4,72392 & 5,09427 & 54,000 & 32 & ,000 \\
\hline
\end{tabular}

Dari hasil tersebut terlihat bahwa rata-rata selisih temperatur pipa segi empat adalah 30,9091 dengan deviasi standar 8,38661, dan pipa bulat 26,0000 dengan deviasi standar 8,48160. Hasil korelasi menunjukkan nilai sebesar 0,998 dengan signifikansi 0,000 , ini berarti ada hubungan yang erat antar sampel dan -korelasi signifikansi secara statistik. Rata-rata perbedaan selisih temperatur air masuk dan keluar 4,909 dengan deviasi standar 0,5552 . Hasil penghitungan t statistik menghasilkan nilai sebesar 54 dengan signifikansi 0,000.

Dengan hasil signifikansi sebesar 0,000 bisa diambil keputusan untuk menolak $\mathrm{Ho}$, karena level signifikansi lebih daripada nilai alpha $(0,025)$.

\section{KESIMPULAN}

Dari hasil pembahasan ini dapat disimpulkan bahwa efisiensi, solar collector dengan pipa segiempat dilengkapi dengan sirip lebih baik dibandingkan dengan yang menggunakan pipa bulat, dengan indikator perbandingan perbedaan temperatur air masuk dan keluar dari kedua prototipe.

\section{DAFTAR PUSTAKA}

[1] Atish Mozumder, Anjani K. Singh, Pragati Sharma, 2014, Study of Cylindrical Honeycomb Solar Collector Hindawi Publishing Corporation Journal of Solar Energy Volume, pp 1-7

[2] A. Kumar, B. N. Prasad. 2000, Investigation of twisted tape inserted solar water heaters heat transfer, friction factor and thermal performance results. Renewable Energy, 19 (3), pp. 379-398.

[3] Alok Kumar, 2014, Performance of Solar Flat plate by using Semi- Circular Cross Sectional Tube, International Journal of Engineering Research and General Science Volume 2, pp 33-37

[4] Budiman Sudia, 2010, Unjuk Kerja Kolektor Surya Plat Datar Menggunakan KonsentratorDua Cermin Datar, DINAMIKA Jurnal IImiah Teknik Mesin, Vol. 1 , No. 2, hal ; $85-90$

[5] D. Bhandari \& Dr. S. Singh, 2012, Performance Analysis of Flat Plate Solar 
Air Collectors With and Without Fins, International Journal of Engineering Research \& Technology IJERT, pp 1-20

[6] E. Azad 2009, Interconnected Heat Pipe Solar Collector, IJE Transactions Vol. 22, No. 3, pp ; 233-242

[7] Grigorios Iordanou, 2009, Flat-Plate Solar Collectors for Water Heating with Improved Heat Transfer for Application in Climatic Conditions of the Mediterranean Region, A thesis submitted in fulfilment of the requirements of the Council of the University of Durham for the Degree of Doctor of Philosophy (PhD), School of Engineering and Computing Science Durham University

[8] H Vettrivel dan P Mathiazhagan 2013, Thermal Performance Optimazion of a Flat Plate Solar Water Heater Collector Using Matlab, International Journal of Mechanical and Production Engineering, Volume-1, pp $14-18$

[9] Hedayatizadeh, M., Ajabshirchi, Y., Sarhaddi, F., Safavinejad, A., Farahat, S., \& Chaji, H. (2013). Thermal and Electrical Assessment of an Integrated Solar Photovoltaic Thermal (PV/T) Water Collector Equipped with a Compound Parabolic Concentrator (CPC). International Journal of Green Energy, 10(5), 494-522. http://dx.doi.org/10.-1080/15435075.2012.678524,12 Januari 2014

[10] Hossein Chaji et al, 2013, Experimental Study on Thermal Efficiency of Flat Plate Solar Collector Using TiO2/WaterNanofluid, Modern Applied Science; Vol. 7, No. 10; pp 60-69

[11] Johan Vestlund 2012, Gas filled, flat plate solar collectors, Thesis for the the defree of doctor of philisophy, Building Services Engineering Department of Energy and Environment Chalmers University of Technology Gothenburg, Sweden,

[12] Ramadhani Bakari, Rwaichi J. A. Minja, Karoli N. Njau, 2014, Effect of Glass Thickness on Performance of Flat Plate Solar Collectors for Fruits Drying, Hindawi Publishing Corporation Journal of Energy Volume 2014, pp 1-8
[13] Raj Thundil Karuppa R., Pavan P.and Reddy Rajeev D , 2012, Experimental Investigation of a New Solar Flat Plate Collector, Research Journal of Engineering Sciences, Vol. 1(4) pp ; 1-8

[14] Taki, M., Ajabshirchi, Y., Behfar, H., \& Taki, M. 2011. Experimental Investigation and Construction of PV Solar Tracker Control System Using Image Processing. Modern Applied Science, 5(6), 237-244. http://dx.doi.org/10.5539/mas.v5n6p237 15 Maret 2014

[15] Vishal Dabra 2013, The effect of tilt angle on the performance of evacuated tube solar air collector: experimental analysis, International Journal of Engineering, Science and Technology Vol. 5, No. 4, pp. 100-110

[16] Yuhazri, M.Y, et al, 2012, Experimental Study on Effect of Reflector Bed Designs eated by Direct Solar Radiation for Hot Water Storage System, International Conference on Design and Concurrent Engineering Universiti Teknikal Malaysia Melaka, pp 458-462 